\title{
La violencia del género: libertad de elección y elección forzada en un caso de transexualidad en la infancia ${ }^{1}$
}

\section{Julieta De Battista}

\begin{abstract}
Resumen
La actualidad nos confronta con una idea ampliamente extendida: cada quien es dueño de su cuerpo y tiene derecho a hacer con él lo que le dé la gana. Los casos de los llamados "transexuales" se presentan como ideales de este poder de decisión sobre el cuerpo y de la reivindicación del derecho a la libertad de elección. Este trabajo propone interrogar tal ideal para volver sobre los efectos de la constelación original en el advenimiento de un sujeto. En 1969, Lacan propuso repensarla en términos de la forma en que le fueron presentados al sujeto el deseo del padre y el de la madre, el modo en que efectivamente se le ofrecieron el saber, el goce y el objeto $a$. Es en estos términos que Lacan sitúa la idea "tramposa" de la elección entre neurosis y psicosis. Tramposa o impropia porque no hubo tal elección, la elección ya estaba hecha a nivel de lo que le fue presentado al sujeto. La elección forzada queda velada tras el ideal del derecho a la libertad de elección. Ahora bien, lo forzado de la elección no ocluye por eso la hipótesis de una posición subjetiva activa. El artículo trabaja esta cuestión en el caso de un niño transexual.
\end{abstract}

\section{Palabras clave:}

Psicoanálisis; Transexualidad; Infancia; Deseo.

\section{Gender violence: freedom of choice and forced choice in a case of childhood transsexuality}

1 Este artículo está basado en el texto de una ponencia y su discusión posterior en el II Simposio Interamericano de la Internacional de los Foros del Campo Lacaniano, que tuvo lugar el 8, 9 y 10 de Septiembre de 2017 en Río de Janeiro. 


\begin{abstract}
Today we are confronted with a widely held idea: everyone owns their body and has the right to do with it whatever they want. The cases of so-called "transsexuals" are presented as ideals of this decision-making power over the body and the claim of the right to freedom of choice. This work proposes to interrogate such ideal to return on the effects of the original constellation in the advent of a subject. In 1969, Lacan proposed to rethink this in terms of the way in which the desire of the father and of the mother was presented to the subject, the way in which knowledge, enjoyment and object $a$ were actually offered to them. It is in these terms that Lacan situates the idea of "cheating" on the choice between neurosis and psychosis. Cheating or improper because there was no such choice, the choice was already made at the level of what was presented to the subject. The forced choice is veiled behind the ideal of the right to freedom of choice. Now, the force of choice does not occlude the hypothesis of an active subjective position. The article addresses this issue in the case of a transsexual child.
\end{abstract}

\title{
Keywords:
}

Psychoanalysis; Transsexuality; Childhood; Desire.

\section{A violência do gênero: liberdade de escolha e escolha forçada em um caso de transexualidade na infância}

\begin{abstract}
Resumo
Hoje, somos confrontados com uma ideia amplamente realizada: todo mundo tem seu corpo e tem o direito de fazer com ele o que quiser. Os casos dos chamados "transexuais" são apresentados como ideais desse poder de decisão sobre o corpo e a reivindicação do direito à liberdade de escolha. Este texto propõe interrogar esse ideal para retornar sobre os efeitos da constelação original no advento de um sujeito. Em 1969, Lacan propôs repensá-lo em termos da maneira como o desejo do pai e da mãe foi apresentado ao sujeito, a maneira como o conhecimento, o gozo e o objeto $a$ lhe foram oferecidos. É nesses termos que Lacan localiza a ideia de "trapaça" da escolha entre neurose e psicose. Enganosa ou imprópria, porque não havia tal escolha, a escolha já foi feita no nível do que foi apresentado ao sujeito. A escolha forçada é velada por trás do ideal do direito à liberdade de escolha. No entanto, a força de escolha não obstrui a hipótese de uma posição subjetiva ativa. O texto trabalha essa questão no caso de uma criança transexual.
\end{abstract}




\title{
Palavras-chave:
}

Psicanálise; Transexualidade; Infância; Desejo.

\section{La violence de genre: liberté de choix et choix forcé dans un cas de transexualité dans l'enfance}

\begin{abstract}
Résumé
Notre temps nous oblige à faire face à une idée largement répandue : chacun possède son propre corps et a le droit d'en faire ce qu'il veut. Les cas des soi-disants "transexuels" sont de très bons exemples de ce pouvoir de prise de décision sur le corps et de revendication au droit à la liberté de choix. Cela dit, ce travail propose d'interroger cet idéal, en examinant les effets de cette constellation originelle dans l'avènement d'un sujet. En 1969, Lacan a proposé de la repenser ayant en compte la façon dont ont été présentés au sujet le désir du père et la mère, la manière dont on lui a effectivement offert la connaissance, la jouissance et l'objet $a$. C'est dans ces termes que Lacan situe l'idée "trompeuse" du choix entre névrose et psychose. Trompeuse ou inappropriée puisqu'il n'y a pas de choix, le choix a déjà été fait au niveau de ce qui a été présenté à ce sujet. Le choix forcé reste voilé derrière l'idéal du droit à la liberté de choix. Or, la contrainte du choix ne masque pas l'hypothèse d'une position subjective active. L'article donc se penchera sur cette question à partir du cas d'un enfant transsexuel.
\end{abstract}

\section{Mots-clés:}

Psychanalyse; Transexualidad; Enfance; Désir.

\section{Introducción}

Desde que en los años 60 los estudios de género comenzaron a visibilizar las diferencias irreductibles que pretenden ser resueltas en la repartición binaria masculino-femenino, el psicoanálisis empezó a ser señalado como una teoría que contribuye a sostener una visión falocéntrica y paternalista del mundo. Comenzó así también a borrarse de un plumazo lo que el psicoanálisis tiene de práctica profundamente transformadora y respetuosa de las máximas diferencias.

Medio siglo después, las reivindicaciones de los estudios de género pasaron a formar parte de la opinión pública y se instalaron en los debates cotidianos sobre las desigualdades que recaen sobre las mujeres y aquellos que se apartan de la norma cis. Sitúo aquí el terreno fértil de la problemática de la que me voy a ocupar, porque entiendo que atañe a la transmisión del psicoanálisis y su situación 
en nuestro estado de la civilización, a lo que se espera de él en nuestro siglo XXI. No creo que sea una cuestión que se juegue a nivel de la puesta en marcha del dispositivo analítico, allí donde rige el deseo de obtener la máxima diferencia, la diferencia absoluta.

Como profesora universitaria de una psicopatología orientada por la lectura de Freud y de Lacan me he encontrado hace ya varios años con que algunos enunciados del psicoanálisis - escuchados a través del cristal de Judith Butler y de las reivindicaciones de género - empezaron a resultar indigeribles para mis jóvenes estudiantes. Quizás esté de más aclarar que en Argentina la carrera de psicología es preponderantemente una facultad conformada en un $90 \%$ por mujeres, situación que entiendo se reitera en otros países. Si a eso le sumamos la ola de asesinatos de mujeres que hoy en Argentina tiene un lugar privilegiado en los medios, la combinación resultaba fatal para poder transmitir algunos principios básicos del psicoanálisis en un contexto que, durante años, ha funcionado como causa para numerosos jóvenes que se encuentran con la lectura de Freud en los primeros momentos de su formación. Transmito algunas de sus preguntas-cuestionamientos: “¿Por qué seguir hablando del Nombre-del-Padre? Eso es sostener el patriarcado que nos oprime y nos termina asesinando", "lo que el psicoanálisis propone para la histeria es un modo de patologizar a las mujeres y acallarlas”, “¿Por qué pensar que Dora tenía una participación activa en la historia con el Sr. K y no denunciar que éste se abusó de ella cuando sólo era una niña?”, “¡Por qué patologizar una elección de género como la de los transexuales diciendo que podría tratarse de una posición psicótica?”. Estimo que adviertan el tono que tiñe a esos interrogantes, su coloratura fuertemente ideológica y la dificultad extra que introducen en la transmisión de principios tan subversivos como los del psicoanálisis en ese contexto: la posición sexualmente activa del niño, la no reducción de la femineidad a la maternidad, la psicosis como posición subjetiva del ser y no como déficit.

Seguramente sigue siendo altamente subversivo (y angustiante) escuchar las tesis freudianas del siglo XX, tan actuales casi un siglo después: el programa de ser felices es irrealizable, el malestar es inescindible de la condición del hombre en la cultura, la fuente de mayor sufrimiento para los hombres proviene de su convivencia con los demás seres humanos (Freud, 1930 [1929]/1991). Más aún cuando la insurgencia ante esas tesis rebota contra su continua constatación: "El infierno son los otros"2, "En este momento oscuro de la civilización nuestra el miserable se llama hombre, sufre en todos los climas, agoniza en todos los idiomas." ${ }^{3}$ En este momento también oscuro de nuestra civilización, el sufrimiento no ha abandonado al ser humano. Sin dudas se trata de una tesis cuya "cientificidad" es difícil de cuestionar, dado su alto grado de replicabilidad y su persistencia a través de la

2 Sartre, J. P. A puerta cerrada.

3 Hugo, V. Los miserables. 
historia. ¿Quién se atrevería a aseverar que está libre del sufrimiento?

La lectura de Lacan tampoco objeta esas tesis y da un paso más al adjudicar la fuente del sufrimiento - el troumatisme que implica el impacto de lalangue en el cuerpo - a la condición de parlêtre del ser humano. El pathos es una elección forzada para el ser humano porque es un ser hablante, la palabra es un parásito, "la palabra es la forma de cáncer que aflige al ser humano” (Lacan, 1975-1976/2005, p. 95). La psicopatología invade la vida cotidiana. Seguramente no hay demasiados oídos prestos a escuchar esta peste y quizás muchos más proclives a soñar con un mundo feliz, exento de las impropiedades del sexo y la muerte, deseosos de una convivencia armónica, dispuestos a curarlo todo con una buena dosis de Soma. ${ }^{4}$ Este deseo de un mundo feliz cotiza alto en la bolsa y además como en ninguna otra época parece que está al alcance de nuestras manos: podemos hacer algo para obtener lo que deseamos, podemos hacer algo para que nuestras sociedades sean más justas e igualitarias, es más, tenemos el derecho de ser felices y debemos hacerlo valer.

La exigencia de paridad ${ }^{5}$ es sumamente tentadora. También lo es la idea del respeto de los derechos humanos y de la libertad de elección sobre el género y sobre el sexo. Cualquier enunciación que tenga la osadía de interrogar los efectos de estos nuevos principios de nuestra civilización corre el riesgo de ser escuchada como una posición anacrónica, machista, troglodita incluso fascista. Rápidamente se puede caer bajo la sospecha de ser simpatizante de los feminicidas, ni qué decir si el que se atreve a interrogar es un varón. Destaco el costado ideológico del asunto, pues contrasta con el estado de nuestras sociedades hoy en día: sociedades en las que - por cierto - sigue rigiendo la segregación urinaria, la adoración de la pregnancia guestáltica del falo ${ }^{6}$ y la añoranza de un padre que ponga orden en este oscuro cambalache. Quizás en otro momento de la civilización afloren problemas diversos: no es descabellado pensar que tal vez el día de mañana ya no importe ser cis o trans, sino ser humano... o no. La inteligencia artificial ya no tendrá que vérselas ni con la sexualidad ni con la muerte.

En esta ocasión quiero compartir con ustedes mis primeros balbuceos al respecto. Decidí empezar por un tema que me interroga especialmente: el de la transexualidad. Reconozco algunos disparadores: la película The danish girl — basada en los diarios de la primera persona que a la que se le practicó un cambio de sexo quirúrgico-; pero también el relato de los profesionales que trabajan con estas

\footnotetext{
4 Huxley, A. Un mundo Feliz.

5 Tomo prestada la expresión "exigencia de paridad" de una conferencia, llamada Lazo social y paridad, que Colette Soler dio en 2015 en la Universidad Nacional de La Plata.

6 Evidentemente el ser humano ha encontrado un gusto especial por erigir monumentos cada vez más altos y no por cavar agujeros cada vez más profundos. El único memorial cuya conformación es un agujero es el del 11/9 en Manhattan. Imposible desconocer su origen.
} 
demandas de readecuación de sexo en función de la identidad de género elegida en un hospital público de la ciudad de La Plata. Me parecía que esos casos nos confrontan con una idea ampliamente extendida hoy en día: cada quien es dueño de su cuerpo y tiene derecho a hacer con él lo que quiera. En el año 2012, se sancionó en Argentina la Ley № 26743 de identidad de género que fue reglamentada en el año 2015. Esa Ley permite que las personas trans (travestis, transexuales, transgénero) sean inscriptas en sus documentos personales con el nombre y el género de elección. Ordena también que los tratamientos médicos de adecuación a la expresión de género elegida sean incluidos en el Programa Médico Obligatorio. Se la ha promocionado como la única ley sobre identidad de género en el mundo que no patologiza la condición trans. Entiendo que aquí el pathos es entendido como discriminación de una diferencia. Pero la expresión "patologizar la condición trans" encierra el riesgo de pensar que acompañar ese proceso de adecuación del cuerpo en función de la identidad de género elegida implicaría la extinción del sufrimiento, supuestamente originado por esa falta de adecuación entre el sexo biológico y la identidad de género asumida.

No patologizar, ¿sería asumir que entonces ya no hay sufrimiento en los sujetos trans que han logrado su readecuación? El sufrimiento de los sujetos trans no se resuelve con la intervención quirúrgica ni con la inscripción del DNI. De acuerdo al relato del equipo ya mencionado que trabaja con estas demandas, luego de la cirugía aparecen otras causas de malestar: la voz no se condice con la identidad de género asumida (con la dificultad agregada de que la voz no puede operarse); el neo-órgano reconstruido se parece bastante al órgano deseado, pero no funciona como sede de excitaciones; la inserción socio-laboral formal de los sujetos trans está plagada de dificultades en muchos casos irremontables y el 85\% obtiene sus ingresos de la prostitución aunque prefieran tener otro empleo. De acuerdo a un estudio de la Organización Mundial de la Salud (OMS) de 2014, la esperanza de vida de la comunidad transexual en Argentina llega sólo a los 41 años, cuando la de la población en general avanza hasta los 75. Las principales causas son los homicidios transfóbicos, el abuso policial y el mal uso de siliconas industriales.

Por un lado, los casos de los transexuales se presentan como ideales de este poder de decisión sobre el cuerpo y de la reivindicación del derecho a la libertad de elección. Sin embargo, por otro lado, este ideal ejercicio de la libertad contrasta con la baja esperanza de vida de los transexuales, la constante segregación y marginalidad, los altos índices de suicidio.

Para adentrarme en este tema, decidí comenzar por una arista especialmente sensible del problema: los casos de transexualidad en la infancia. Voy a ofrecer una lectura del relato testimonial de la madre de un niño que antes de sus dos años comienza a decir que es una nena y no un nene. El caso cobró relevancia en nuestro país por tratarse del primer niño trans de 6 años a quien se le otorga un 
cambio de DNI, reconociendo la asunción de una identidad de género diferente a tan corta edad. Es conocido por las conquistas que implicó para la comunidad trans en Argentina. Voy a ahorrarles toda la vertiente de reconocimiento y empoderamiento de la defensa de los derechos que el caso suscitó y cuyo valor es incuestionable, para abocarme a las manifestaciones del sufrimiento en este caso. Insisto en el punto en que no se trata de patologizar la condición trans, sino de interrogar la forma del pathos que asedia a todo ser humano. Interrogar la expresión que ese Pathos universal encuentra en la singularidad irreductible de cada quien y que, a fuerza de querer despatologizarlo, corre el riesgo de dejar de ser escuchado.

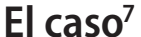

Manuel y Federico son mellizos, los primeros hijos de Gabriela. Pero no los de Guillermo - el papá - , quien al momento de nacer ellos ya había abandonado a otros tres hijos. Gabriela transcurre todo su embarazo de alto riesgo y los primeros años de la crianza con el temor de que estos hijos también serán abandonados por el padre. La marca del abandono insiste en las generaciones: ella misma es la tercera hermana mujer, criada por una madre que quedó sola. El padre de Gabriela también abandonó a sus hijos y desapareció. La madre de Gabriela, "luchadora nata", creó sola a sus cuatro hijos: "nos dio el amor y el cuidado de madre y nunca nos faltó nada, aunque no tuviéramos un padre" (Mansilla, 2014, p. 63).

El padre de los mellizos imaginaba un futuro para estos dos varones: trabajarían juntos, uno sería electricista como él, el otro mecánico. Gabriela insiste una y otra vez en que ella no deseaba una nena, mucho menos "la parejita": "Me puse feliz cuando me dijeron que eran dos varones. Pensaba que de ser nenas iban a sufrir un montón. Pero siendo varones, estudiar, conseguir un trabajo, salir... todo es más fácil para ellos, ¿no?” Esta asociación entre “ser niña” y “sufrir” parece comandar su interpretación de las primeras conductas de sus bebés: mientras que Federico no pedía nada, dormía bien y era muy tranquilo; Manuel era muy demandante, llamaba todo el tiempo la atención, lloraba desconsoladamente y no dormía bien, dormía muy poco: "A tu hermano lo conformaba enseguida y a vos no conseguía calmarte. (...) Nada te complacía, siempre necesitabas algo que yo no podía descifrar porque ni siquiera hablabas. Eran tan diferentes, el día y la noche. A él se lo notaba sereno, tranquilo; en cambio a vos algo no te dejaba en paz. Se notaba en tu mirada, sorprendían tus ojitos profundamente tristes" (Mansilla, 2014, p. 25). La diferencia también aparecía en los juegos: a Manuel no le gustaba jugar "a lo bruto", era muy sensible y no quería jugar con el papá. Uno parecía estar bien en su cuerpo, el otro sufría sin motivo, siempre "disconforme".

7 Todas las citas de este apartado son del libro escrito por Gabriela Mansilla, Yo nena, yo princesa, en la edición de la Universidad Nacional de General Sarmiento de 2014. 
Según relata la madre, un episodio casual cuando Manuel tenía dos años - la visión de la película de La bella y la bestia - parece poner un nombre a esta diferencia en el cuerpo: Manuel baila como Bella, queda deslumbrado por esa princesa y toma prestadas remeras de la madre para bailar. A partir de entonces el vestirse con la ropa de la madre se vuelve algo cotidiano "te pasabas todo el día con una remera mía puest” (Mansilla, 2014, p. 27). Y las noches también, porque escondía las remeras debajo de la almohada. Las noches sin dormir, los terrores nocturnos y el llanto continuo sin sentido acompañan estos días donde lo único que parece calmarlo son los vestidos de la madre. A esos episodios de "llanto desgarrador" se fueron sumando otras conductas autodestructivas: tirarse del pelo hasta producir la caída de mechones enteros, golpearse la cabeza contra la pared, morderse. También sufría de asma. Manuel tenía apenas dos años, "no tenías paz, no lograba entenderte". Un cuerpo que pide a gritos ser vestido, ¿es por eso un cuerpo de mujer?

La madre cuenta que cuando Manuel pudo hablar, a los 20 meses, lo primero que dijo fue: "Yo nena, yo princesa" y allí se selló para ella el inicio de una "larga lucha”, la del reconocimiento de que Manuel había nacido con un cuerpo de varón, pero deseaba ser una nena. La diferencia entre ambos hermanos se nombra como una cuestión de género, la experiencia de lo insoportable de ese cuerpo pasa a reconducirse a una disconformidad entre lo que se ve y lo que se es. Las prácticas de Manuel de cubrirse con cualquier tela o género que encontraba - repasadores, remeras, fundas, toallas, trapos de piso - eran siempre interpretadas como el deseo de ser una nena: "como si fueran vestidos", "como si quisiera tener pelo largo", "como si fuera princesa". Aunque por momentos el relato de la madre deja entrever que quizás la problemática iba un poco más allá de la diferencia de los sexos y de los géneros, y parecía concernir más bien a los bordes de un cuerpo que se pudiera habitar: "todavía escucho tus gritos cada vez que te sacaba lo que te habías puesto, no te estaba sacando la ropa, yo sentía que te estaba arrancando la piel" (Mansilla, 2014, p. 31). Los desbordes críticos de Manuel continuaban. La constitución de la consistencia del cuerpo es un dato previo a los dos tiempos de la elección sexuada.

A partir del enunciado "Yo nena, yo princesa", todo se encamina a acompañar a Manuel en lo que se interpreta como su deseo de ser nena y su elección de identidad, a acompañarlo, no reprimirlo, escucharlo y ayudarlo a convertirse en "la princesa más hermosa del mundo" (Mansilla, 2014, p. 36), el recorrido de "cómo pasaste de ser mi nene a ser Luana, mi princesa” (Mansilla, 2014, p. 25). Luana, es el nombre elegido por el niño. Aparecen entonces las pelucas de cotillón, los disfraces de princesa, las muñecas y también las resistencias: “¿Por qué le comprás revistas de nena a él?", "para vos hay autitos, no muñecas”. Los otros se niegan a 
venderle a un niño una revista de princesas o un vestido, las maestras del jardín lo obligan a actuar como varón; no lo dejaban ser lo que él quería y tenía derecho a ser: una nena. Alguna vacilación ocasional de Manuel no encuentra tampoco demasiado lugar, ante la pregunta de la madre acerca de si está jugando como una nena porque usaba una funda de almohada como vestido, responde: "No, mamá, estoy bailando, yo soy un nene", Gabriela acota a continuación que el niño sólo había aprendido a decir lo que ellos querían escuchar.

El padre también se opone a acompañar este cambio, que para la madre se va imponiendo en su necesidad con mayor convicción. El padre lo permite a regañadientes, en la intimidad de la casa, pero no acepta que Manuel salga a la calle vestido de nena, tampoco acepta comprarle muñecas que, no obstante, la madre le promete. El padre empieza a convertirse para la madre en "nuestro mayor obstáculo” (Mansilla, 2014, p. 56). Ella insistía en que el padre debía reconocer el deseo de su hijo de ser una nena, para ella el padre "Estaba entre la espada y la pared. Entre tener un varón deshecho y con miedo o una nena con pene" (Mansilla, 2014, p. 49). Los comportamientos auto-agresivos de Manuel continuaban siendo interpretados como una reacción ante la no aceptación del deseo de ser una nena "te destruías en nuestra cara" (Mansilla, 2014, p. 46). La situación se vuelve intolerable para el padre, quien ante las continuas demandas de la madre accede a comprarle una muñeca, pero luego no puede ni mirar ni saludar a su hijo, sólo lo evade. Si bien la madre sostiene que el padre comenzó a aceptar que su hijo era una nena, en un momento el padre estrella una botella vacía contra el piso sin reparar en que allí se encontraba Luana. El padre comienza a ausentarse, se va por varios días, hasta que un día no vuelve más. Para la madre se abre allí algo nuevo: "Si podía luchar y enfrentar a tu papá, podía con todos" (Mansilla, 2014, p. 63), "en el fondo de mi corazón, sabía que algún día se iba a ir. Cuando lo conocí a papá, ya tenía tres hijos a los cuales había abandonado y ese era el gran temor que yo tenía, que hiciera lo mismo y nos dejara a nosotros también" (Mansilla, 2014, p. 47). La madre "luchadora" es también un rasgo de las mujeres de su familia.

Pero las resistencias no son sólo del padre, también son de los otros y quizás las más insistentes provienen del cuerpo mismo, de una parte que molesta: el "penecito". Manuel ya tiene cuatro años y cambió su nombre por el de Luana; pero el pene sigue allí y esa parte del cuerpo ha quedado sin función, es negada. No quiere hacer pis ni caca para no verse, empieza a hacerse pis encima: "No tengo penecito porque soy nena". Curiosamente en este caso, la diferencia entre los sexos no pasa por la premisa universal del pene, sino que de entrada aparece enunciada como "las nenas tienen vagina y los nenes tienen pene". La madre propone que es una "nena diferente, especial, una nena con pene", pero eso no basta, Luana replica: "A mí me gustaría ser una nena común” (Mansilla, 2014, p. 66). El temor 
de la madre de que Luana se lastime o corte su pene va en aumento, al punto de que guarda todos los elementos cortantes.

En tanto, todo lo que Luana hace insiste en ser interpretado en la misma clave del género: "necesitabas ser nena para estar bien (...) mamá te acompañaba en tu deseo de ser y de convertirte en la nena que sos" (Mansilla, 2014, p. 95) y llevaba a un nuevo escalón en la lucha de la reivindicación por los derechos: que el jardín acepte que es una nena, que el Estado le cambie el Documento Nacional de Identidad (DNI). Ninguno de estos avances logra, sin embargo, detener algunas conductas que se reiteran: la disconformidad no cede, el llanto desconsolado tampoco, las pesadillas menos, se sigue lastimando, se sigue despertando a los gritos en la noche, se muerde, se arranca el pelo, se rasguña la cara. Pero este sufrimiento se encuentra nuevamente con la misma interpretación: "A gritos pedías que te aceptaran, a gritos rogabas que te dejaran ser una nena” (Mansilla, 2014, p. 73); “Tu deseo de ser nena era tan fuerte, tan intenso, necesario, había tanto instinto en vos, tanta esencia femenina, que todo aquel que te conoció pudo percibirlo" (Mansilla, 2014, p. 115). El deseo de la niña la transforma también en una luchadora de la que hay que aprender, a la que hay que saber escuchar y acompañar: "Percibiste tu identidad mucho antes de saber cuál era la diferencia física entre un nene y una nena. (...) Hoy sos más nena que las nenas que conozco" (Mansilla, 2014, p. 115).

Sin embargo, vestirse de nena, tener un DNI de nena, ser llamada como una nena y ser aceptada como nena las veinticuatro horas no calma el sufrimiento del cuerpo. Luana tiene ya cinco años y no cesa en rasguñarse la cara, en tirarse del pelo, morderse los dedos, pegarse en la cara hasta lastimarse y lo hace adelante de todos. Aparecen las escenas en que enfrenta a la madre y se vuelve hostil con Federico: quería que su hermano también fuera una princesa con pene. En ocasión de un acto escolar, Luana se para en el medio del patio adelante de todos y mirando a su madre empieza a rasguñarse la cara con las dos manos hasta lastimarse (Mansilla, 2014, p. 167). Acababa de ver en el baño a una nena y su vagina. Las preguntas por la función del pene y de los testículos insisten, ¿para qué sirven?, pregunta Luana. La madre contesta: "Sirven para que el día de mañana construyan una vagina si vos querés. El día que vos no quieras más tu penecito, mamá te va a llevar a un doctor que puede transformar ese pene y testículos en una vagina" (Mansilla, 2014, p. 110), “¿Puedo tener bebés? Quiero un bebé nena y la quiero tener en mi panza” (Mansilla, 2014, p. 127).

La presencia del pene parece llevar a Luana a vacilar:

No quiero ir más a ese jardín mamá. Cortame el pelo y decime Manuel (...) Es que yo tengo que ser un nene.

¿Por qué tenés que serlo?

Porque tengo pene.

Pero vos sos una nena diferente. 
Los nenes tienen pene, entonces tengo que ser un nene. (Mansilla, 2014, p. 104)

¿Para qué sirven los órganos fuera de un discurso establecido? El intento de la madre de poblar su pequeño mundo fabricando muñecas con pene no puede evitar la presencia real de ese órgano cuya existencia ahora puede negarse, pero que retornará vigorizado con los embates de la pubertad.

\section{Discusión}

Este caso generó muchas controversias entre los psicoanalistas de nuestro país. Por un lado, encontramos la lectura de quienes acompañaron a Luana y a su madre, cuya posición es clara y puede seguirse en el testimonio. Es la posición de una mirada que se pretende despatologizadora y que por eso puede acompañar el deseo de transformación de Luana, defendiendo su fuerza arrolladora. En esta lectura ese deseo debe ser escuchado, acompañado, no reprimido y el deseo mismo se convierte en un derecho primero: el derecho al deseo. Ahora bien, esta lectura tiende a diluir la idea de Lacan de que el deseo es el deseo del Otro y de que el deseo es su interpretación.

Por otro lado, se alzan las voces de protesta que defienden los tiempos de la constitución subjetiva, señalando el pasaje necesario por la alienación del deseo del niño al deseo de los padres, pero también su posterior separación. No es mi intención volver aquí sobre las teorías que encuentran en la culpabilización de la madre el resorte de la posición del niño. Sí quiero retomar la idea de Lacan sobre los efectos de la constelación original en el advenimiento de un sujeto y recordar que no se trata tampoco de un determinismo absoluto, sino que implica la posición activa del niño ante esa oferta. Es una tercera posible lectura del caso que intenta avanzar en la senda de interrogar al deseo y no simplemente acompañarlo en su afirmación o sostenerlo en su alienación, sino recuperar su potencial de corte, de separación, de constitución subjetiva. Sin desconocer por esto ni las condiciones de posibilidad del deseo, ni ahogar su fuerza en la alienación. Es una lectura que rescata la importancia de al menos dos tiempos en la elección y en la constitución subjetiva. Son dos tiempos cuyo recorrido no debe cortocircuitarse, sino que su apertura inaugura la interrogación del deseo, la diferencia absoluta, en su posible disponibilidad al lazo social.

En 1969, Lacan propuso repensar la biografía original en términos de la forma en que le fueron presentados al sujeto el deseo del padre y el de la madre, el modo en que efectivamente se le ofrecieron el saber, el goce y el objeto $a$. Es en estos términos que Lacan sitúa la idea "tramposa" de la elección entre neurosis y psicosis. Tramposa o impropia porque no hubo tal elección, la elección ya estaba hecha a nivel de lo que le fue presentado al sujeto. De este modo Lacan llama la atención sobre las condiciones de la oferta en las que un sujeto puede advenir y de qué 
manera. Allí ya hay una elección, pero una elección que antecede, una elección forzada, un primer tiempo.

Lacan (1967/2001) ha insistido sobre esta idea de la constelación original que precede al advenimiento de un sujeto y con respecto a la cual éste puede constituirse. Recordó esas leyes dialécticas que extrajo de las observaciones de Cooper: es necesario el trabajo de dos generaciones para obtener un niño psicótico, él mismo es el fruto de la tercera. Olvidar el estatuto del fantasma es caer en la idea tramposa de que hay una elección subjetiva entre neurosis, perversión y psicosis. Hay algo ya establecido al momento de la llegada del recién nacido. Se trata entonces de saber si el niño sirve o no, dice Lacan, como objeto transicional para la madre, si sirve o no como objeto condensador de su goce, si realiza o no la presencia de este objeto, si soborna o no al fantasma materno y qué papel juega en este entuerto el padre.

No hay elección entre neurosis y psicosis, esa elección está forzada por las condiciones de lo que efectivamente se ofreció al recién llegado. En cambio, sí entiendo que hay elección entre psicosis y debilidad mental, y quizás este puede ser uno de los sentidos posibles de la afirmación de Lacan en 1976-1977 "entre locura y debilidad mental, no tenemos sino la elección". Es una elección que concierne a un segundo tiempo, a la posibilidad de constituirse subjetivamente y salir de la posición de realización del objeto del fantasma materno, aunque no por la carretera principal que ofrece el Nombre-del-Padre. La posición del débil, holofraseado con su madre, no habilita a que se instale sólidamente como sujeto, queda flotando entre dos discursos, tal y como Lacan lo recuerda 11/12/1972 en ...Ou pire (1971-1972/2011).

En cambio, la psicosis sí implica un movimiento de separación, de constitución del sujeto bajo la forma del rechazo forclusivo. Se trataría entonces de un rechazo que se da en dos tiempos, un doble rechazo. El rechazo primordial del significante del Nombre-del-Padre, Ur-Verwerfung, que deja como alternativa el ubicarse como objeto del oscuro deseo materno sin posibilidad de que un sujeto se constituya por esta vía, quedando alienado al discurso del Otro previo. Pero habría un rechazo secundario, un rechazo que separa de esta existencia alienada y da lugar a un deseo otro, un deseo original que surge del doble rechazo de la oferta primordial que presidió al nacimiento. En este rechazo secundario encuentro la posibilidad de la constitución subjetiva del psicótico, la salida de la posición del débil mental por la locura. Es la posición subjetiva de quien no consiente a quedar reducido a ser el mero soporte del deseo materno.

Esta intuición no deja de tener su asidero en la experiencia clínica de los analistas que trabajan con estos niños y de la cual Maud Mannoni dejó numerosos testimonios ${ }^{8}$ : el hecho de que la intervención del analista que apunta a localizar

8 Véanse las obras de M. Mannoni: El niño retardado y su madre y La primera entrevista con el psicoanalista. 
al sujeto en la díada holofrásica del débil mental y su madre provoca la psicotización del primero. Lacan (1964/1981) deslizó la idea al evocar cómo "la dimensión psicótica se introduce en la educación del débil” (Lacan, 1964/1981, p. 215). En esa serie de casos aunados por la holofrase - el efecto psicosomático, la debilidad mental y las psicosis - hay sin embargo diferencias porque el sujeto no ocupa en cada una de ellas el mismo lugar. La dimensión psicótica se introduce en la debilidad mental en ese punto en el cual el débil pasa a ubicarse como sujeto, dejando de quedar reducido a ser el mero soporte del oscuro deseo de la madre. Un sujeto se constituye en ese rechazo a partir de la emergencia de un deseo, que en su operación de corte separa. Ahora bien, el débil mental se anuda holofrásicamente al cuerpo de la madre y en esa solidificación parece resolver la consistencia del cuerpo por la vía de convertirse en objeto de los cuidados y la protección de la madre, con el goce que esto conlleva. La salida de esta posición y la constitución subjetiva que implica ese rechazo secundario entraña irremediablemente un desanudamiento de la consistencia del cuerpo, una soltura de lo imaginario, un dejar caer el cuerpo propio de las psicosis.

\section{Conclusiones}

Me pregunto si en el caso de Luana la elección forzada no queda velada tras el ideal del derecho a la libertad de elección. Las condiciones de la oferta se prestan al rechazo y el significante "nena" parece adquirir una pendiente holofrásica, es la respuesta iterativa a todas las preguntas. Entre esas condiciones de la oferta entiendo que habría que incluir también a lo que llamo la violencia del género, que forma parte de lo que precede. Hay a este respecto algo que funciona como un discurso establecido: el de la adecuación entre el sexo biológico y el género. Discurso del amo que dice qué hay que hacer con los cuerpos y los órganos, un modo establecido de hacer lazo social. Esta forma de hacer lazo sostiene tradicionalmente: "Si tiene genitales masculinos hace de hombre, si tiene genitales femeninos hace de mujer". Se impone desde la elección del nombre, los vestidos, el trato. Es un modo de hacer lazo que está establecido y como tal asigna funciones al cuerpo. Ahora bien, lo forzado de la elección no ocluye por eso la hipótesis de una posición subjetiva activa, pero entiendo que esa elección atañe al hecho de aceptar o rechazar las formas establecidas de hacer lazo.

En una primera lectura del caso se podría pensar que el deseo inconsciente de la madre acerca del sexo del niño fue determinante en su transformación. Pero quizás este caso nos confronta con la existencia de un deseo que se asienta en el deseo de los padres, pero bajo la forma del rechazo, un deseo que no es efecto de la père-version. Entiendo entonces que puede haber deseos originales que no se apoyan en una transmisión, sino que surgen de un rechazo de lo establecido, de lo ofertado. Son deseos que subvierten lo establecido, están orientados a lo real y 
se confrontan con cómo hacer con un cuerpo que rehúye las formas tradicionales de hacer lazo. Deseos trans, que no se conforman con el rechazo de lo establecido, sino que se empeñan en transformar la realidad.

\section{Referencias bibliográficas}

Freud, S. (1930 [1929]/1991). El malestar en la cultura. In J. Strachey (Ed.). Obras completas (Vol. 21, 2a. ed., pp. 57-140). Buenos Aires: Amorrortu.

Lacan, J. (1964/1981). Le séminaire, livre 11: les quatre concepts fondamentaux de la psychanalyse. Paris: Seuil.

Lacan, J. (1967/2001). Allocution sur les psychoses de l'enfant. In Lacan, J. Autres écrits (pp. 361-371). Paris: Seuil.

Lacan, J. (1969/2001). Note sur l'enfant. In J. Lacan Autres écrits (pp. 373-374). Paris: Seuil.

Lacan, J. (1971-1972/2011). Le séminaire, livre 19: ...ou pire. Paris: Seuil.

Lacan, J. (1975-1976/2005). Le séminaire, livre 23: le sinthome. Paris: Seuil.

Lacan, J. (1976-1977). Le séminaire, livre 24: l'insu que sait de l'une bévue s'aile a mourre. Inédito.

Mansilla, G. (2014). Yo nena, yo princesa. Luana, la niña que eligió su propio nombre. Buenos Aires: Universidad Nacional de General Sarmiento.

República Argentina (2015). Ley nº 26.743. De identidad de género.

Recebido: 15/10/2017

Aprovado: 09/01/2018 